\title{
The immediate effects of patellar taping on balance and gait ability in individuals with chronic stroke
}

\author{
Jin Shin ${ }^{a}$, Mee-Hyang Mun ${ }^{b}$, Yijung Chung ${ }^{c}$ \\ ${ }^{a}$ Department of Physical Therapy, Gyeong-In Rehabilitation Center Hospital, Incheon, Republic of Korea \\ ${ }^{b}$ Physical Therapy Team, Yonsei University College of Medicine, Seoul, Republic of Korea \\ 'Department of Physical Therapy, College of Health and Welfare, Sahmyook University, Seoul, Republic of Korea
}

Objective: The aim of this study is to investigate the effect of patellar taping on balance and gait abilities in chronic stroke patients.

Design: Randomized placebo-controlled trial.

Methods: Thirty chronic stroke patients who have been diagnosed at least six months or before were recruited from R hospital. These study subjects were randomized to the experimental group $(\mathrm{n}=15)$ or placebo group $(\mathrm{n}=15)$. In the experimental group, patellar taping was applied while for the placebo group, placebo taping was applied. The Balance System SD was used for measuring dynamic standing balance in these two groups. In addition, the GAITRite (CIR System Inc.) system was utilized for calculating gait performance in these patients.

Results: After application of taping, the patellar taping group showed a significant decrease in dynamic standing balance in their sway area $(p<0.05)$. However, in the placebo group, there was no significant difference in dynamic standing balance ability and gait ability before and after application of taping. Comparison of the patellar taping group and placebo group showed significant differences in dynamic standing balance ability and gait performance $(p<0.05)$.

Conclusions: From the results of this study, it appears that application of patellar taping in chronic stroke patients significantly improved dynamic standing balance ability and gait ability in these patients. Based on these results, patellar taping is thought to be useful in real clinical settings where there are many chronic patients who are in need of improvement in their balance and gait ability.

Key Words: Athletic tape, Gait, Patella, Postural balance, Stroke

\section{Introduction}

Stroke is a serious global health problem. Aspects of disabilities caused by stroke are various according to the affected region and its severity. In general, sensory deficits, cognitive problems, motor impairments, visual perceptual disorders and dysphagia mainly occur among stroke patients $[1,2]$. In particular, postural sway, abnormal weight bearing or decreased standing ability may occur due to imbalance [3]. Also, decreased ability in having balance can be caused by decreased range of motion, muscular weakening, changes in muscle tone, sensory deficits, abnormal postural responses and cognitive problem [4]. Furthermore, abnormality in balance may increase the probability of falls, thus increasing social economic costs $[5,6]$.

For improving balance ability in stroke patients, various studies have been conducted. They include visual feedback training [3,7], dynamic balance control training [8], body weight shift control training [9,10], motor learning [11], task oriented training [12], Tai-chi program [13], and virtual-reality training [14]. Each of these studies has confirmed the effect of balance training in stroke patients.

Received: 24 September, 2014 Revised: 3 November, 2014 Accepted: 25 November, 2014

Corresponding author: Yijung Chung

Department of Physical Therapy, College of Health and Welfare, Sahmyook University, 815 Hwarang-ro, Nowon-gu, Seoul 139-742, Republic of Korea Tel: 82-2-3399-1637 Fax: 82-2-3399-1639 E-mail: yijung36@syu.ac.kr

(c) This is an Open-Access article distributed under the terms of the Creative Commons Attribution Non-Commercial License (http://creativecommons.org/licens es/by-nc/3.0) which permits unrestricted non-commercial use, distribution, and reproduction in any medium, provided the original work is properly cited.

Copyright @ 2014 Korean Academy of Physical Therapy Rehabilitation Science 
Also, gait is one of the most prominent physical factors (marker) in assessing severity of stroke patients. Various gait factors exist; slow gait frequency, gait velocity, asymmetry between affected legs and less-affected legs, short stance phase of affected side, decrease in gait ability due to long swing phase compared to less-affected side [15], or decrease in endurance can be the main cause of degradation in independent activity of daily living ability [16].

Many studies were performed to increase gait ability of stroke patients. For example, progressive resistance exercise of low extremities [17-19], robot treadmill gait training [20-22], feed-back training [23-25], treadmill gait training [26-28], virtual-reality training [14,29-32] were conducted to prove the effect of each training on stroke patients.

Many studies have proven the effectiveness of taping in solving gait and balance problem in stroke patients. Taping helps protect and support joints while they perform functional movement [33]. Taping can also help increase kinetic stability of movement [34]. According to previous studies on taping in post-stroke patients, during the stance phase gait, application of gluteal taping resulted in improvement of hip joint extension [35]. In addition, Kinesio taping performed on stroke patients was reported to improve bio-electrical activation of the vastus medialis [36].

Almost all of stroke patients showed tightness in their gastrocnemius muscle and weakness in their gluteus medius muscle on their affected side. Gastrocnemius tightness may limit ankle dorsiflexion, which can result in increased subtalar joint pronation and tibial internal rotation, contributing to abnormal pulling of the patellar tendon and the patellar malalignment [37]. Dysfunction of the gluteus medius muscle may induce excessive internal rotation at the hip. Increased internal rotation of the hip can contribute to a greater valgus force vector at the knee, thus resulting in patellar malalignment [38]. To ensure functional efficacy of patients, maintaining the patellar alignment in the trochlear groove of the femur is necessary [39]. Patellar taping effectively realigns the location of the patella. McConnell introduced a rehabilitation program incorporates patellar taping techniques to improve patellar tracking within the patellofemoral groove, as well as stretching of the lateral knee soft tissues, vastus medialis oblique strengthening, and closed kinetic chain training [40].

However, up to date, there have been a lack of studies about balance and gait ability in hemiplegia stroke patients. In particular, application of taping for patellar and its effect on balance and gait abilities in hemiplegia patient is very rare. Therefore, in this study, the effect of patellar taping on gait and dynamic balance control ability in chronic stroke patients was investigated. This study tried to provide better clinical therapy techniques based on real life for chronic stroke patients.

\section{Methods}

\section{Subjects}

From July to August 2014, thirty stroke patients who were hospitalized in the Incheon Redcross Hospital in Incheon were recruited. These patients were divided randomly into two groups (patellar taping group, placebo group). Subject inclusion criteria was: hemiplegia patients who were diagnosed with stroke 6 months ago or longer, patients who can walk independently at least 10 meters, patients who have neither hemianopia nor dysopsia and patients who had a Mini-Mental State Examination-Korean (MMSE-K) score of more than 21. The study was approved by the institutional ethics committee, and participants signed a written informed consent prior to participation.

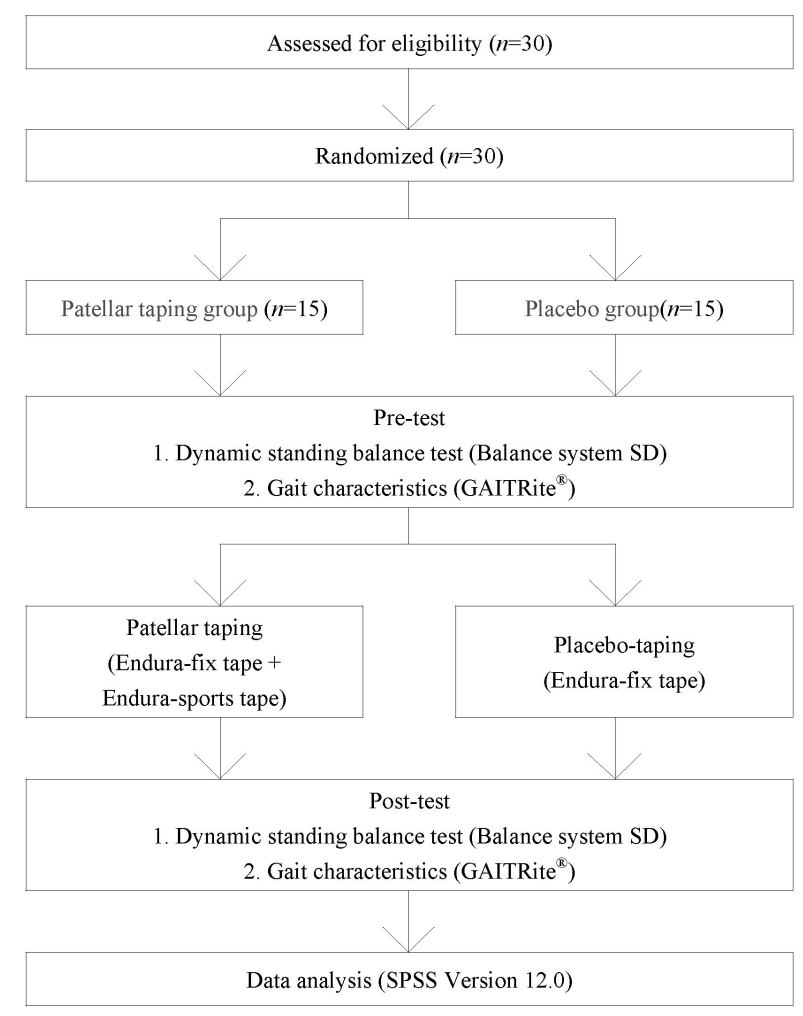

Figure 1. Flow diagram of total experimental procedure. 

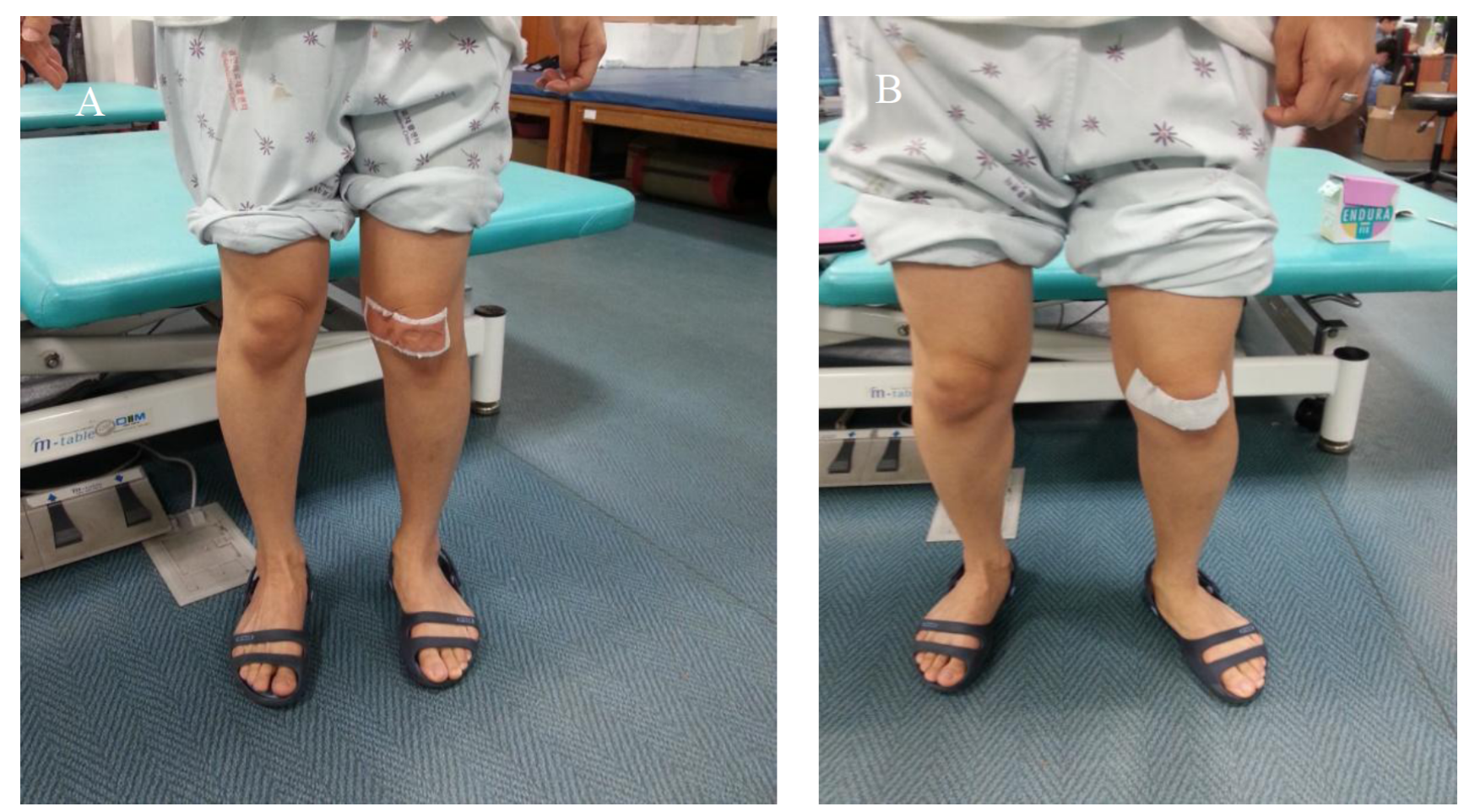

Figure 2. Taping method. (A) Patellar taping. (B) placebo taping.

\section{Procedures}

This study was conducted as a pre-post test (Figure 1). Thirty chronic stroke patients who corresponded to the inclusion criteria were randomized to either the patellar taping group ( $n=15)$ or placebo group $(n=15)$. Patellar taping group applied McConell taping on their knee joints. In contrast, the placebo group applied placebo taping on the equal side of knee joint. Before taping, dynamic standing balance ability and gait performance (velocity, cadence, step length, stride length) were pre-tested. Thirty minutes after taping, the same region where the pre-test was done were also analysed for comparison. At both pre and post test, subjects took a rest to allow for adaptation.

In the patellar taping group, non-elastic Endura-sports tape (OPTP, Minneapolis, MN, USA) and elastic Endura-fix tape (OPTP) were used as patellar-intervention. In placebo group, elastic tape Endura-fix tape was used for the intervention. In the patellar taping group, McConnell taping [40] was applied where the knee joint was pushed toward the inside to induce medial attraction, and then were taped. The advanced fixing tape was attached to prevent the skin from slipping and then non-elastic tape was attached on to it. In the placebo group, subjects were taped at the same place as patellar tap- ing without inducing the medial attraction of the knee joint (Figure 2).

To measure dynamic standing balance control ability, Balance System SD (Biodex Medical Systems, Shirley, NY, USA) was used. This Balance System SD is consisted of five analyzing programs: 1) movable round pad which can be directed both toward unstable anterior-posterior or medial-lateral direction, 2) target-screen monitor, 3) movement sensor, 4) data analyzing computer, and 5) printing machine. This study utilized postural stability test (PST) of the Balance system SD. In the PST, anterior-posterior, medial-lateral balance distribution was displayed on the screen. Also, scores for total anterior-posterior and medial-lateral were processed in the computer and printed out. The higher the balance score, the lower the balance ability of the patient. The intraclass correlation coefficient of this tool (program) is $\mathrm{r}=0.80$ [41].

This study used GAITRite (CIR System Inc., Clifton, NJ, USA) to measure the gait factor (element) of subjects. Gait, temporal and spatial factors (velocity, cadence, step length, stride length) of patellar taping group were analyzed and compared to the that of the placebo group. All gait within the correlation coefficient was more than 0.96 at comfort gait velocity state [42]. 
Table 1. General characteristics of the subjects $(\mathrm{N}=30)$

\begin{tabular}{lcrrr}
\hline & Patellar taping group $(\mathrm{n}=15)$ & Placebo group $(\mathrm{n}=15)$ & $X^{2} / t$ & $p$ \\
\hline Sex (male/female) & $9 / 6(60.0 / 40.0)$ & $4 / 11(26.7 / 73.3)$ & 3.394 & 0.650 \\
Paretic side (right/left) & $5 / 10(33.3 / 61.7)$ & $8 / 7(53.3 / 46.7)$ & 1.222 & 0.269 \\
Etiology (infarction/hemorrhage) & $10 / 5(66.7 / 33.3)$ & $12 / 3(80.0 / 20.0)$ & 0.682 & 0.409 \\
Height (cm) & $165.53(6.79)$ & $167.80(10.86)$ & -1.153 & 0.499 \\
Age (y) & $56.20(13.67)$ & $48.93(10.44)$ & -0.514 & 0.113 \\
Post-stroke duration (mo) & $9.60(2.30)$ & $10.41(2.79)$ & -0.447 & 0.655 \\
Brunnstrom stages (score) & $3.85(0.69)$ & $3.57(0.78)$ & -0.835 & 0.404 \\
Mini-Mental State Examination-Korean (score) & $26.71(2.13)$ & $26.14(1.95)$ & -0.519 & 0.604 \\
\hline
\end{tabular}

Values are presented as $\mathrm{n}(\%)$ or mean (SD).

Table 2. Comparison of dynamic standing balance

$(\mathrm{N}=30)$

\begin{tabular}{|c|c|c|c|c|}
\hline & Patellar taping group $(n=15)$ & placebo group $(n=15)$ & $t$ & $p$ \\
\hline \multicolumn{5}{|c|}{ Dynamic standing balance (score) } \\
\hline Pre-test & $3.77(1.44)$ & $3.06(1.11)$ & 1.457 & 0.157 \\
\hline Post-test & $2.45(0.85)$ & $2.82(1.03)$ & & \\
\hline Changes & $1.32(0.75)$ & $0.24(0.61)$ & 4.123 & 0.000 \\
\hline
\end{tabular}

Values are presented as mean (SD).

\section{Data and statistical analysis}

Statistical analyses were conducted using the SPSS ver. 12.0 (SPSS Inc., Chicago, IL, USA). The baseline characteristics between two groups were compared using $x^{2}$ test. Between-group comparisons of the changes between the pre-test and post-test were performed using the paired t-test, Within-group comparisons were performed using the independent t-test. Statistical significance was established as $p<0.05$.

\section{Results}

No significant differences were evident between the patellar taping and placebo group in baseline characteristics (Table 1).

\section{Dynamic balance and spatiotemporal gait parameters}

Changes in dynamic standing balance control ability between pre- and post application of patellar taping is listed in Table 2. In the patellar taping group, before applying patellar taping, dynamic standing balance control ability was 3.77 (1.44). After applying patellar taping, dynamic standing balance control score was significantly decreased to $2.45(0.85)$ $(p<0.05)$. In the placebo group, before applying placebo taping, dynamic standing balance score was 3.06 (1.11). After applying placebo taping, dynamic standing balance control ability was 2.82 (1.03) and there was no significant difference. Comparison of changes in dynamic balance control ability between both groups were made. In the patellar taping group, the change value was $1.32(0.75)$. In the placebo group, the change value was $0.24(0.61)$. There was a statistically significant difference between these two groups $(p<0.05)$ (Figure 3).

Changes in gait parameters after patellar taping are listed in Table 3. Before applying patellar taping, gait velocity was 38.49 (16.76) cm/sec; after applying patellar taping, gait velocity was $46.13(18.94) \mathrm{cm} / \mathrm{sec}$, and there was a significant difference $(p<0.05)$. Before applying placebo taping, gait velocity was $34.73(11.07) \mathrm{cm} / \mathrm{sec}$. After applying placebo taping, gait velocity was $35.84(11.21) \mathrm{cm} / \mathrm{sec}$ and there was no significant difference.

For gait velocity change in pre-post application, changes in the patellar taping group was $-7.64(9.32) \mathrm{cm} / \mathrm{sec}$; in the placebo group, the change was $-1.11(2.87) \mathrm{cm} / \mathrm{sec}$. There was a significant difference between the two groups $(p<0.05)$ (Figure 4).

Before applying patellar taping, cadence was 64.98 (14.02) steps/min. After application, cadence was significantly increased to 74.39 (15.27) steps/min $(p<0.05)$. Before applying placebo taping, cadence was 62.25 (9.75) steps/min. After application, cadence was 63.86 (10.57) steps/min and there was no significance improvement.

For cadence changes in pre-post applications, changes in 


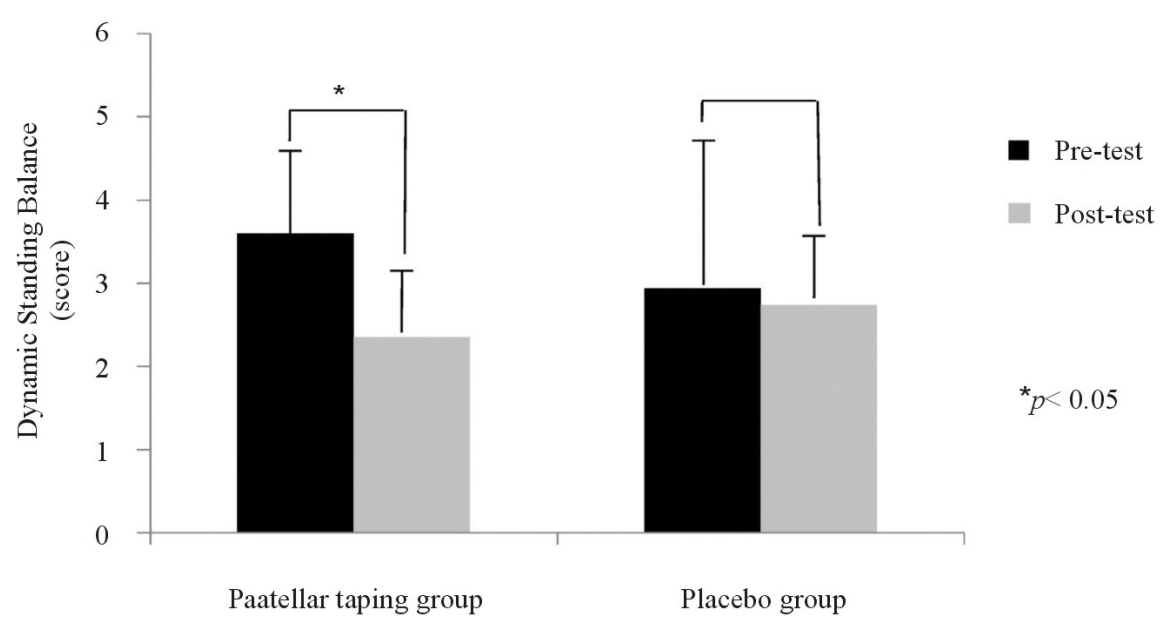

Figure 3. Comparison of dynamic standing balance.

Table 3. Comparison of gait parameters within the groups and between the groups

$(\mathrm{N}=30)$

\begin{tabular}{|c|c|c|c|c|}
\hline & Patellar taping group $(n=15)$ & Placebo group $(n=15)$ & $t$ & $p$ \\
\hline \multicolumn{5}{|c|}{ Velocity $(\mathrm{cm} / \mathrm{sec})$} \\
\hline Pre-test & $38.49(16.76)$ & $34.73(11.07)$ & 0.700 & 0.490 \\
\hline Post-test & $46.13(18.94)$ & $35.84(11.21)$ & & \\
\hline Changes & $-7.64(9.32)$ & $-1.11(2.87)$ & -2.507 & 0.019 \\
\hline \multicolumn{5}{|c|}{ Cadence (steps/min) } \\
\hline Pre-test & $64.98(14.02)$ & $62.25(9.75)$ & 1.025 & 0.315 \\
\hline Post-test & $74.39(15.27)$ & $63.86(10.57)$ & & \\
\hline Changes & $-9.41(8.10)$ & $-1.61(5.06)$ & -3.025 & 0.006 \\
\hline \multicolumn{5}{|c|}{ Step length $(\mathrm{cm})$} \\
\hline Pre-test & $30.04(8.47)$ & $31.42(5.85)$ & -0.502 & 0.620 \\
\hline Post-test & $34.16(8.50)$ & $33.32(6.71)$ & & \\
\hline Changes & $-4.11(4.57)$ & $-1.89(3.73)$ & -1.407 & 0.171 \\
\hline \multicolumn{5}{|c|}{ Stride length (cm) } \\
\hline Pre-test & $58.91(17.69)$ & $63.13(12.67)$ & -0.725 & 0.475 \\
\hline Post-test & $65.01(19.66)$ & $65.24(11.97)$ & & \\
\hline Changes & $-6.09(8.55)$ & $-2.11(4.55)$ & -1.537 & 0.140 \\
\hline
\end{tabular}

Values are presented as mean (SD).

the patellar taping group was $-9.41(8.10)$ steps/min and for the placebo group, the change was -1.61 (5.06) steps/min. These results imply a significant improvement between the patellar taping group and the placebo group $(p<0.05)$ (Figure 5).

Before applying patellar taping, step length was 30.04 $(8.47) \mathrm{cm}$; after application, the step length was significantly increased to $34.16(8.50) \mathrm{cm}(p<0.05)$. Before placebo taping, step length was $31.42(5.85) \mathrm{cm}$; after application, step length was $33.32(6.71) \mathrm{cm}$ and there was no significant improvement. Pre-and post application changes between two groups were not significant (Figure 6).

Before applying patellar taping, stride length was 58.91 (17.69) cm; after application, stride length was significantly increased to $65.01(19.66) \mathrm{cm}(p<0.05)$. Before placebo tap- ing, stride length was $63.13(12.67) \mathrm{cm}$; after application, stride length was $65.24(11.97) \mathrm{cm}$ and there was no significant improvement. There were no significant changes in stride length in pre- and post application between the two groups (Figure 7).

\section{Discussion}

This study was conducted to investigate the effect of knee joint-patellar taping applied on improving dynamic standing balance control ability and gait ability in chronic stroke patients.

Pfeiffer et al. [43] reported that the McConnell patellartaping program is intended to correct patellar tracking by medializing the patella, allowing patients to engage in phys- 


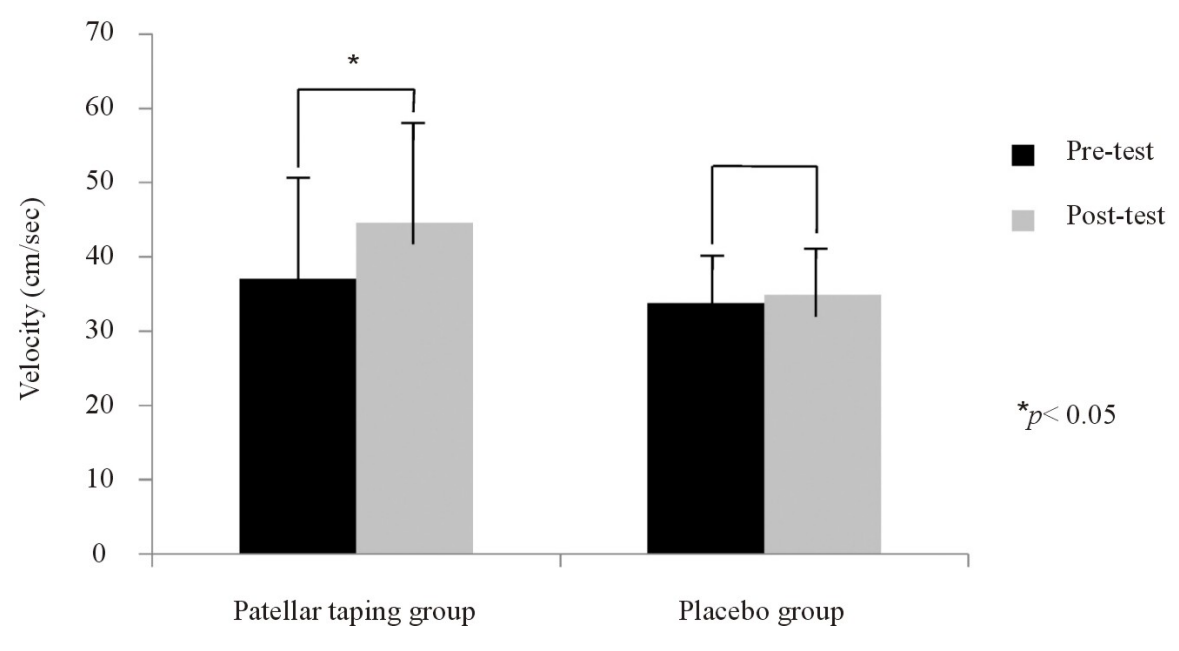

Figure 4. Comparison of velocity.

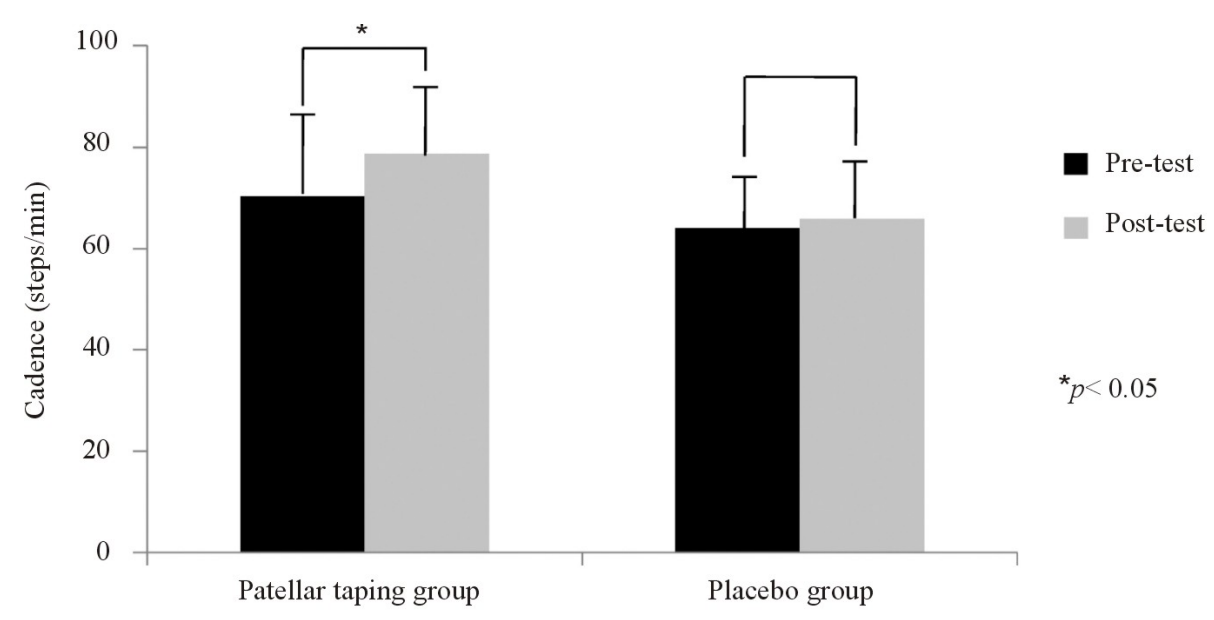

Figure 5. Comparison of cadence.

ical therapy exercise. Ernst et al. [44] showed that patellar taping on knee joint improved the alignment of the patella and stability of knee joints. Also, patella taping brought beneficial effects on balance ability of knee joint and function of lower extremity. In knee osteoarthritic patients, Crossley [45] confirmed that non-elastic taping immediately softened the inflammation tissues and improved the alignment of the lower extremity, thus enhancing their balance ability and physical posture.

As was proved in previous studies, this study also showed significant improvement in dynamic standing balance following patella taping on knee joints (Table 2). In contrast, placebo group showed no significant changes in their dynamic standing abilities. From this, we can assume that patellar taping improvement in balance ability is not caused from psychologic factors of patients. Rather it is estimated that patellar taping re-positions the patellar and aligns the symmetry of it, leading to rise in stability and dynamic standing balance ability.

Patellar taping, contrary to placebo taping, imposes pressure on joint when it is applied. This pressure can provide stability on the joint. However, placebo taping applied on the same area as that of the patellar taping showed no changes in this area.

From this result, we can suggest that simple stimulation of proprioception by taping is not effective in improving standing balance in stroke patients. Pressure of taping is a more important factor in providing stability and improving dynamic standing balance ability of knee joints. This method, providing stability on lower extremity joints in stroke patients, has a common concept with an ankle foot orthosis, which is used for balance ability in stroke patients [46].

According to Allet et al. [47], asymmetrical weight bearing imposed on stroke patients enhanced control ability in the less affected lower extremity. This led to changes in compensation, thus aggravating asymmetry in gait pattern 

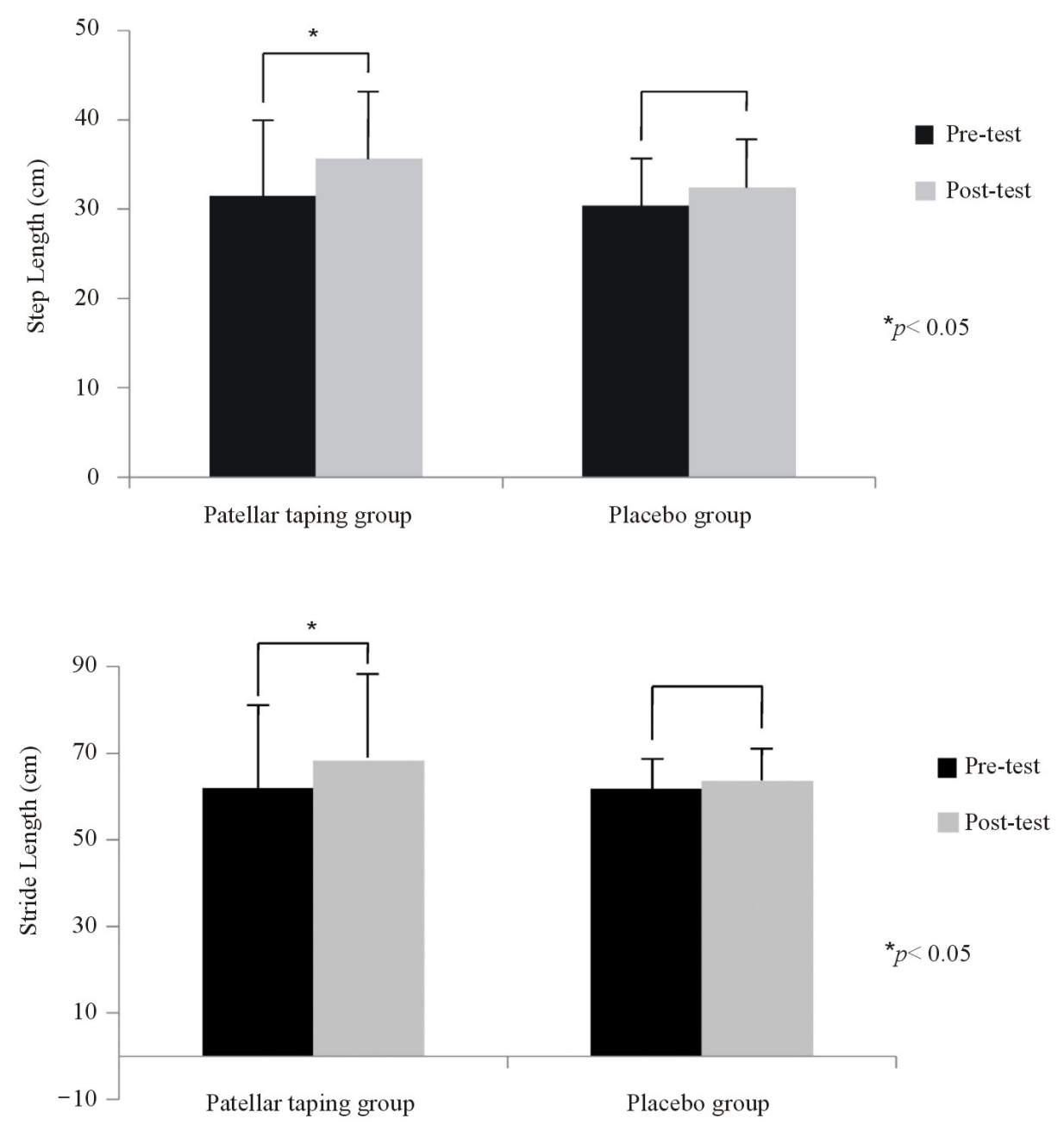

Figure 6. Comparison of step length.

Figure 7. Comparison of stride length.

of stroke patients. In the swing phase of the affected lower limb, decreased muscle power in lifting foot delayed the swing phase time, and this leads to decreased ability in moving weight towards the affected side [48]. Therefore, in treating stroke patients, asymmetrical alignment of lower limb should be considered, and estimation of gait variation to compare asymmetric relationship in gait is very important.

Lin et al. [49] reported on gait performance and lower limb's motor function, and the correlation of joint positional sense based on twenty-five patients. In this study, changes in ankle joint positional sensory made a significant difference in gait velocity and stride length. Carse et al. [50] conducted a study on eight patients who were diagnosed with stroke. In this study, the effect of lower limb re-alignment on gait was investigated. The results showed that the walking velocity, overall average step length and cadence were significantly increased from 0.22 to $0.36 \mathrm{~m} / \mathrm{s}, 0.28$ to $0.37 \mathrm{~m}, 45$ to 56 steps/min respectively. Also, Lewek et al. [51] reported a case study based on two chronic stroke patients. In this study, after conducting a proprioceptive feedback program, both patients improved gait speed and spatiotemporal symmetry.

From this study, after application of patellar taping, there was significant changes in gait variables such as cadence, step length, stride length, gait velocity $(p<0.05)$. However, similar to balance ability, the placebo group showed no significant changes in gait parameters.

Patellar taping used in this study enhanced patellar tracking in the patellofemoral groove and this result in complete range of motion and re-alignment without causing pain. Therefore, patellar taping can be used to improve functional status of patients who were physically disabled due to various diseases [43].

McConnell patellar taping method is used to maintain positional fault corrected by repositioning. The application of 
patellar taping enhances joint position sense and proprioception through skin, tendon, and muscle stimulation. This process reduces pain and helps assists in patient recovery. We can conclude that applied and re-aligned region of the patella and enhancement of proprioception has led to the improvement in gait ability.

Due to the small sample size, chronological changes in data of stroke patients were difficult to attain. Therefore, it is difficult to generalize the results of this study this study in the clinical world. Also, this study only measured dynamic standing balance among various balance types. In further studies, the effect of patellar taping on various balance types should be investigated to generalize the results on all types of stroke patients. From these limitations, follow-up tests would be appropriate to compensate for the limitations of this study.

Patellar taping application significantly increased dynamic standing balance ability and gait ability in chronic stroke patients. Therefore, if patellar taping is applied to stroke patients, asymmetrical alignment in body and dynamic standing control ability and gait ability would be improved in great amounts.

\section{Conflict of Interest}

The authors declared no potential conflicts of interest with respect to the authorship and/or publication of this article.

\section{References}

1. Mercier L, Audet T, Hébert R, Rochette A, Dubois MF. Impact of motor, cognitive, and perceptual disorders on ability to perform activities of daily living after stroke. Stroke 2001;32:2602-8

2. Ozdemir F, Birtane M, Tabatabaei R, Ekuklu G, Kokino S. Cognitive evaluation and functional outcome after stroke. Am J Phys Med Rehabil 2001;80:410-5.

3. Srivastava A, Taly AB, Gupta A, Kumar S, Murali T. Post-stroke balance training: role of force platform with visual feedback technique. J Neurol Sci 2009;287:89-93.

4. Bonan IV, Colle FM, Guichard JP, Vicaut E, Eisenfisz M, Tran Ba Huy $\mathrm{P}$, et al. Reliance on visual information after stroke. Part I: Balance on dynamic posturography. Arch Phys Med Rehabil 2004;85:268-73

5. Belgen B, Beninato M, Sullivan PE, Narielwalla K. The association of balance capacity and falls self-efficacy with history of falling in community-dwelling people with chronic stroke. Arch Phys Med Rehabil 2006;87:554-61.

6. de Oliveira CB, de Medeiros IR, Frota NA, Greters ME, Conforto AB. Balance control in hemiparetic stroke patients: main tools for evaluation. J Rehabil Res Dev 2008;45:1215-26.

7. Yavuzer G, Eser F, Karakus D, Karaoglan B, Stam HJ. The effects of balance training on gait late after stroke: a randomized controlled trial. Clin Rehabil 2006;20:960-9.

8. Worms G, Matjacić Z, Gollee H, Cikajlo I, Goljar N, Hunt KJ. Dynamic balance training with sensory electrical stimulation in chronic stroke patients. Conf Proc IEEE Eng Med Biol Soc 2006;1:2150-3

9. Dean CM, Channon EF, Hall JM. Sitting training early after stroke improves sitting ability and quality and carries over to standing up but not to walking: a randomised trial. Aust J Physiother 2007;53:97-102.

10. Verheyden G, Nieuwboer A, De Wit L, Thijs V, Dobbelaere J, Devos H, et al. Time course of trunk, arm, leg, and functional recovery after ischemic stroke. Neurorehabil Neural Repair 2008;22:173-9.

11. Lord SE, Rochester L, Weatherall M, McPherson KM, McNaughton HK. The effect of environment and task on gait parameters after stroke: A randomized comparison of measurement conditions. Arch Phys Med Rehabil 2006;87:967-73.

12. French B, Thomas LH, Leathley MJ, Sutton CJ, McAdam J, Forster A, et al. Repetitive task training for improving functional ability after stroke. Cochrane Database Syst Rev 2007;(4): CD006073.

13. Au-Yeung SS, Hui-Chan CW, Tang JC. Short-form Tai Chi improves standing balance of people with chronic stroke. Neurorehabil Neural Repair 2009;23:515-22.

14. Flynn S, Palma P, Bender A. Feasibility of using the Sony PlayStation 2 gaming platform for an individual poststroke: a case report. J Neurol Phys Ther 2007;31:180-9.

15. Mauritz KH. Gait training in hemiplegia. Eur J Neurol 2002;9 Suppl 1:23-9; dicussion 53-61.

16. Chen RY, Lim JK, Chuo AM. Stroke audit. Med J Malaysia 2003;58:330-6.

17. Flansbjer UB, Miller M, Downham D, Lexell J. Progressive resistance training after stroke: effects on muscle strength, muscle tone, gait performance and perceived participation. J Rehabil Med 2008;40:42-8

18. Lee MJ, Kilbreath SL, Singh MF, Zeman B, Lord SR, Raymond $\mathrm{J}$, Davis GM. Comparison of effect of aerobic cycle training and progressive resistance training on walking ability after stroke: a randomized sham exercise-controlled study. J Am Geriatr Soc 2008;56:976-85.

19. Lexell J, Flansbjer UB. Muscle strength training, gait performance and physiotherapy after stroke. Minerva Med 2008;99: 353-68.

20. Freivogel S, Schmalohr D, Mehrholz J. Improved walking ability and reduced therapeutic stress with an electromechanical gait device. J Rehabil Med 2009;41:734-9.

21. Kakou H, Shitama H, Kimura Y, Nakamoto Y, Furuta N, Honda $\mathrm{K}$, et al. Walking assist robot and its clinical application. J UOEH 2009;31:207-18.

22. Schwartz I, Sajin A, Fisher I, Neeb M, Shochina M, Katz-Leurer $\mathrm{M}$, et al. The effectiveness of locomotor therapy using robotic-assisted gait training in subacute stroke patients: a randomized controlled trial. PM R 2009;1:516-23.

23. Aruin AS, Hanke TA, Sharma A. Base of support feedback in gait rehabilitation. Int J Rehabil Res 2003;26:309-12. 
24. Schauer M, Mauritz KH. Musical motor feedback (MMF) in walking hemiparetic stroke patients: randomized trials of gait improvement. Clin Rehabil 2003;17:713-22.

25. Krishnamoorthy V, Hsu WL, Kesar TM, Benoit DL, Banala SK, Perumal R, et al. Gait training after stroke: a pilot study combining a gravity-balanced orthosis, functional electrical stimulation, and visual feedback. J Neurol Phys Ther 2008;32:192-202.

26. Enzinger C, Dawes H, Johansen-Berg H, Wade D, Bogdanovic $\mathrm{M}$, Collett J, et al. Brain activity changes associated with treadmill training after stroke. Stroke 2009;40:2460-7.

27. Franceschini M, Carda S, Agosti M, Antenucci R, Malgrati D, Cisari C; Gruppo Italiano Studio Allevio Carico Ictus. Walking after stroke: what does treadmill training with body weight support add to overground gait training in patients early after stroke?: a single-blind, randomized, controlled trial. Stroke 2009;40:3079-85.

28. Roerdink M, Lamoth CJ, van Kordelaar J, Elich P, Konijnenbelt M, Kwakkel G, et al. Rhythm perturbations in acoustically paced treadmill walking after stroke. Neurorehabil Neural Repair 2009;23:668-78.

29. Dunning K, Levine P, Schmitt L, Israel S, Fulk G. An ankle to computer virtual reality system for improving gait and function in a person 9 months poststroke. Top Stroke Rehabil 2008; 15:602-10.

30. Lotan M, Yalon-Chamovitz S, Weiss PL. Improving physical fitness of individuals with intellectual and developmental disability through a Virtual Reality Intervention Program. Res Dev Disabil 2009;30:229-39.

31. Yang YR, Tsai MP, Chuang TY, Sung WH, Wang RY. Virtual reality-based training improves community ambulation in individuals with stroke: a randomized controlled trial. Gait Posture 2008;28:201-6.

32. Mirelman A, Bonato P, Deutsch JE. Effects of training with a robot-virtual reality system compared with a robot alone on the gait of individuals after stroke. Stroke 2009;40:169-74.

33. Cools AM, Witvrouw EE, Danneels LA, Cambier DC. Does taping influence electromyographic muscle activity in the scapular rotators in healthy shoulders? Man Ther 2002;7:154-62.

34. McCaw ST, Cerullo JF. Prophylactic ankle stabilizers affect ankle joint kinematics during drop landings. Med Sci Sports Exerc 1999;31:702-7.

35. Kilbreath SL, Perkins S, Crosbie J, McConnell J. Gluteal taping improves hip extension during stance phase of walking following stroke. Aust J Physiother 2006;52:53-6.

36. Słupik A, Dwornik M, Białoszewski D, Zych E. Effect of Kinesio Taping on bioelectrical activity of vastus medialis muscle. Preliminary report. Ortop Traumatol Rehabil 2007;9: 644-51.

37. Nyland JA, Ullery LR, Caborn DN. Medial patellar taping changes the peak plantar force location and timing of female basketball players. Gait Posture 2002;15:146-52.

38. Brindle TJ, Mattacola C, McCrory J. Electromyographic changes in the gluteus medius during stair ascent and descent in subjects with anterior knee pain. Knee Surg Sports Traumatol Arthrosc 2003;11:244-51.

39. Aminaka N, Gribble PA. A systematic review of the effects of therapeutic taping on patellofemoral pain syndrome. J Athl Train 2005;40:341-51.

40. Mc CJ. The management of chondromalacia patellae: a long term solution. Aust J Physiother 1986;32:215-23.

41. Pereira HM, de Campos TF, Santos MB, Cardoso JR, Garcia Mde $\mathrm{C}$, Cohen M. Influence of knee position on the postural stability index registered by the Biodex Stability System. Gait Posture 2008;28:668-72.

42. van Uden CJ, Besser MP. Test-retest reliability of temporal and spatial gait characteristics measured with an instrumented walkway system (GAITRite). BMC Musculoskelet Disord 2004; 5:13.

43. Pfeiffer RP, DeBeliso M, Shea KG, Kelley L, Irmischer B, Harris C. Kinematic MRI assessment of McConnell taping before and after exercise. Am J Sports Med 2004;32:621-8.

44. Ernst GP, Kawaguchi J, Saliba E. Effect of patellar taping on knee kinetics of patients with patellofemoral pain syndrome. J Orthop Sports Phys Ther 1999;29:661-7.

45. Crossley K, Cowan SM, Bennell KL, McConnell J. Patellar taping: is clinical success supported by scientific evidence? Man Ther 2000;5:142-50.

46. Cakar E, Durmus O, Tekin L, Dincer U, Kiralp MZ. The ankle-foot orthosis improves balance and reduces fall risk of chronic spastic hemiparetic patients. Eur J Phys Rehabil Med 2010;46:363-8.

47. Allet L, Leemann B, Guyen E, Murphy L, Monnin D, Herrmann FR, et al. Effect of different walking aids on walking capacity of patients with poststroke hemiparesis. Arch Phys Med Rehabil 2009;90:1408-13.

48. Patterson KK, Parafianowicz I, Danells CJ, Closson V, Verrier MC, Staines WR, et al. Gait asymmetry in community-ambulating stroke survivors. Arch Phys Med Rehabil 2008;89:304-10.

49. Lin PY, Yang YR, Cheng SJ, Wang RY. The relation between ankle impairments and gait velocity and symmetry in people with stroke. Arch Phys Med Rehabil 2006;87:562-8.

50. Carse B, Bowers R, Meadows BC, Rowe P. The immediate effects of fitting and tuning solid ankle-foot orthoses in early stroke rehabilitation. Prosthet Orthot Int 2014. [Epub ahead of print]

51. Lewek MD, Feasel J, Wentz E, Brooks FP Jr, Whitton MC. Use of visual and proprioceptive feedback to improve gait speed and spatiotemporal symmetry following chronic stroke: a case series. Phys Ther 2012;92:748-56. 